\title{
RIBOFLAVIN STATUS IN LATE PREGNANCY, POSTPARTUM AND CORD BLOOD
}

\author{
Ning-Sing Shaw, PhD \\ Department of Agricultural Chemistry, National Taiwan University \\ Taipei, Taiwan
}

\begin{abstract}
Riboflavin status of 61 pregnant Chinese women was investigated in a longitudinal study by functional assay of the coenzyme activation of erythrocyte glutathione reductase. Maternal nonfasting venous blood was collected at 26 and 36 gestational weeks and 6 weeks postpartum. At delivery, 27 pairs of maternal and cord blood samples were also collected. Dietary intake of riboflavin was estimated by 24-hour recall method at the 26th gestational week. Judged by an activation coefficient $>1.25$, the prevalence of riboflavin deficiency was $31 \%$ to $45 \%$ in late pregnancy and $34 \%$ postpartum. Cord blood exhibited better riboflavin status than the maternal blood, and there was significant correlation between the two. Of all the subjects, $47.5 \%$ had a daily riboflavin intake less than the recommended dietary allowances for pregnancy.

Prevalence of deficiency was highest in subjects whose diet included neither milk nor prenantal vitamin supplement. Therefore, prenatal supplementation is recommended for pregnancy in order to guarantee an adequate supply of riboflavin.
\end{abstract}

Key words: Riboflavin status, Erythrocyte glutathione reductase, Pregnancy, Postpartum, Cord blood

\section{INTRODUCTION}

Riboflavin is an essential cofactor in cellular oxidation. It is necessary for fetal growth and development. Milk and dairy products are important riboflavin sources, but these foods are less frequently consumed as compared to Western countries by Chinese adults due to lactose intolerance. The riboflavin status of populations in Taiwan has been evaluated by dietary survey and the functional 
assessment of the coenzyme activation of erythrocyte glutathione reductase (EGR, EC 1.6.4.2). A national dietary survey in Taiwan area conducted in 198081 (1) indicated that average daily riboflavin intake per person was $0.9 \mathrm{mg}$, reaching only 75\% RDNA ( Recommended Daily Nutrient Allowances, a Chinese version equivalent to RDA of U.S.A.)(2). At that same time, survey for pregnant women in rural and urban area resulted in a daily intake of $69 \%$ and $85 \%$ of RDNA respectively (3), and frequency of an activation coefficient (AC) of EGR $>1.2$ was $58.5 \%$ and $45 \%$ respectively (3). In this past decade, Taiwan's economic level and living standard has risen significantly, and the general public has an increased knowledges in nutrition and health. A recent national dietary survey conducted in 1986-88 (4) indicated an increase of riboflavin intake to $1.03 \mathrm{mg} / \mathrm{day}$, reaching $84 \%$ of the RDNA. People in general are aware of increased maternal nutrient demand during pregnancy. It was not known whether riboflavin status of pregnant women was improved parallelly. This study updated the understanding by investigating the riboflavin status in late pregnancy, postpartum and cord blood with the EGR assay.

\section{MATERIALS AND METHODS}

\section{Subject}

In August and September of 1990,61 healthy pregnant women were selected randomly from the patients attending the Antenatal Clinic Of Veterans General Hospital, Taipei, to participate in this study. The study was reviewed and approved by the Committee on Clinical Research of the Veterans General Hospital-Taipei, and informed consent was obtained from each subject at the beginning of the study. The subjects were recruited at $26 \pm 2$ gestational weeks. Their average age was $29 \pm 4$ yrs, average pregestational weight was $50.5 \pm 5.0$ $\mathrm{Kg}$, and average height was $158.7 \pm 4.2 \mathrm{~cm}$. Forty of them were primigravida, and all had uneventful full-term deliveries. None of the subjects was anemic in her first trimester, was not diagnosed with any clinical symptoms of deficiency and received no prescribed supplements. However, self-chosen prenatal supplements were not excluded, and 27 subjects took $40 \mathrm{mg}$ iron supplement per day from 26th gestational week to term, and 21 subjects took prenatal vitamin and mineral supplement (New Prenatal) regularly, which contained 2 $\mathrm{mg}$ of riboblavin per tablet. Dietary data were collected by 24-hour dietary recall at 26 gestational weeks, and was computer analyzed using Chinese food composition tables $(5,6)$.

\section{Blood collection and analysis}

Nonfasting venous blood samples were drawn at 26 (26wk) and 36 (36wk) gestational weeks and 6 weeks postpartum (6PP), and 61, 43 and 41 samples were collected at each period respectively, among which 30 constituted true longitudinal samples. Twenty-seven pairs of maternal and cord 
blood were drawn at delivery. Blood samples were collected in heparinized tubes and erythrocytes were washed thoroughly with saline after separation from plasma by centrifugation. The in vitro activation of EGR with FAD was measured by the procedures of Tollotson and Sauberlich (7). The change of absorbance at $340 \mathrm{~nm}$ was followed for $10 \mathrm{~min}$ in both the presence and absence of added FAD. The results were calculated and presented as AC, which is the ratio between absorbance change with FAD and that without FAD. A ratio $>1.25$ is considered indicative of riboflavin deficiency, with values $>1.4$ indicating severe deficiency and values between 1.25 and 1.4 indicating marginal deficiency $(8,9)$.

The differences among periods and among food groups were evaluated with Duncan's multiple range test. Correlation was evaluated by Pearson's correlation test.

\section{BESULT}

The distribution of AC EGR at each period is presented in figure 1. The average $A C$ at $26 w k$ and $36 w k$ and $6 P P$ was $1.21 \pm 0.18,1.21 \pm 0.15$ and $1.22 \pm 0.13$ respectively, among which there is no significant difference $(p>$ 0.05 ). The mean $A C$ for the 30 subjects followed at each of the three periods showed similar results. Judged by $A C$, the frequency of marginal deficiency was $16 \%$ at $26 \mathrm{wk}, 33 \%$ at $36 \mathrm{wk}$ and $22 \%$ at $6 \mathrm{PP}$; the frequency of severe deficiency was $15 \%$ at $26 \mathrm{wk}, 12 \%$ at $36 \mathrm{wk}$ and $12 \%$ at $6 \mathrm{PP}$; and total frequency of deficiency was $31 \%$ at $26 \mathrm{wk}, 45 \%$ at $36 \mathrm{wk}$ and $34 \%$ at $6 \mathrm{PP}$. Among these three periods the highest incidence of deficiency occurred in $36 \mathrm{wk}$.

At delivery, $A C$ was $1.27 \pm 0.19$ for maternal blood and $1.07 \pm 0.10$ for cord blood. About $59 \%$ of maternal AC was $>1.25(26 \%>1.4$ and $33 \%$ between 1.25 and 1.4). The $A C$ of the cord blood was significantly lower than that of maternal blood from both in late pregnancy and at delivery $(p<0.01)$. Out of 27 cord blood samples, none exhibited severe deficiency, and 4 were very close to marginal deficiency, of which all can be traced to mothers with severe deficiency. Correlation coefficients are listed in table 1. Significant correlation existed between all periods of sampling $(p<0.001-0.05)$ except between cord blood and 6PP.

The daily riboflavin intake and prevalence of deficiency are listed in table 2. In order to further investigate the effect of riboflavin sources on the status, the subjects were divided into four dietary groups according to whether milk or prenatal vitamin supplement was consumed or not: group A did not consume either milk or supplement; group B consumed milk; group $\mathrm{C}$ did not consume milk but took supplement; group D consumed both milk and supplement. Results for these four groups are listed in table 2. 


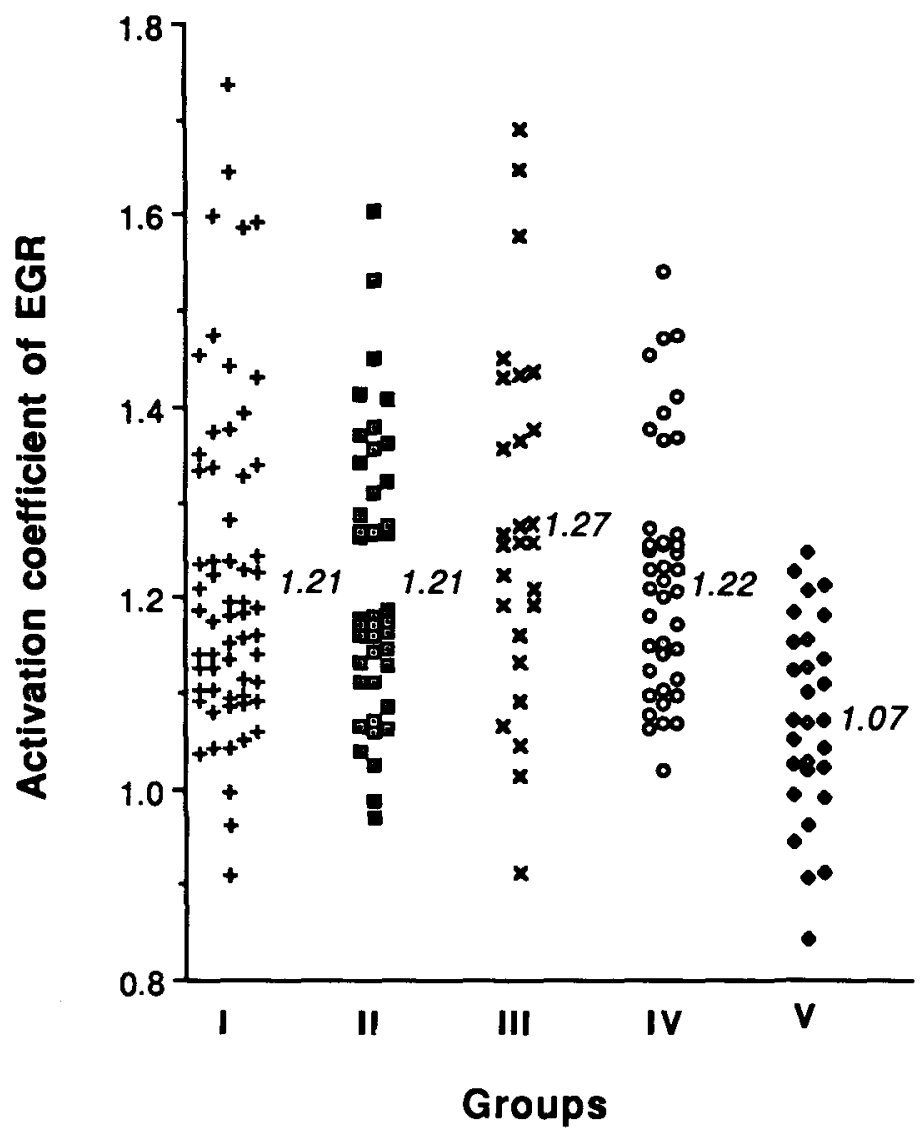

Fig. 1

Distribution And Mean of Activation Coefficient of Erythrocyte Glutathione Reductase (EGR) of 26 (I) and 36 (II) Gestational Weeks, 6 Weeks Postpartum (IV), and Maternal (III) and Cord Blood (V) at Delivery. 
TABLE 1

Correlation Analysis of Erythrocyte Glutathione Reductase Activation Coefficient in Late Pregnancy, Postpartum and Cord Blood

\begin{tabular}{|c|c|c|c|c|}
\hline & \multicolumn{2}{|c|}{ Gestational weeks } & \multicolumn{2}{|c|}{ At delivery } \\
\hline & $26 \mathrm{wk}$ & 36 wk & maternal & cord \\
\hline $\begin{array}{l}\text { Gestation } \\
36 \text { wk }\end{array}$ & $0.3788^{C}(43)$ & 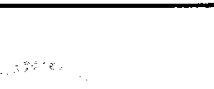 & & \\
\hline $\begin{array}{l}\text { At delivery } \\
\text { maternal } \\
\text { cord }\end{array}$ & $\begin{array}{l}0.6535^{a}(27) \\
0.3942^{c}(27)\end{array}$ & $\begin{array}{l}0.6556^{\mathrm{a}}(22) \\
0.6370^{\mathrm{b}}(22)\end{array}$ & $0.6826^{a}(27)$ & \\
\hline $\begin{array}{l}\text { Postpartum } \\
6 \mathrm{PP}\end{array}$ & $0.5002^{\mathrm{b}}(41)$ & $0.6458^{a}(32)$ & $0.6352^{b}(17)$ & $0.3355(17)$ \\
\hline
\end{tabular}

$(n)$ indicates number of subjects; $a: p<0.001, b: p<0.01, c: p<0.05$

\section{TABLE 2}

Daily Riboflavin Intake and Prevalence of Deficiency at 26th Gestational Week

\begin{tabular}{llllll}
\hline & & \multicolumn{4}{c}{ Dietary groups } \\
\cline { 3 - 6 } & Total & $\begin{array}{l}\mathrm{A} \\
\text { diet }\end{array}$ & $\begin{array}{l}\mathrm{B} \\
+ \text { milk }\end{array}$ & $\begin{array}{l}\mathrm{C} \\
+ \text { supple- } \\
\text { ment }\end{array}$ & $\begin{array}{l}\text { D } \\
+ \text { milk+ } \\
\text { supplement }\end{array}$ \\
\hline Subject & 61 & 8 & 23 & 12 & 18 \\
numbers & & & & & \\
Daily riboflavin intake (mg) & & & & \\
mean \pm s.d. & $2.24 \pm 1.37$ & $0.99 \pm 0.32 \mathrm{~b}$ & $1.14 \pm 0.49 \mathrm{~b}$ & $3.41 \pm 1.35 \mathrm{a}$ & $3.24 \pm 0.76 \mathrm{a}$ \\
range & $0.24-6.03$ & $0.39-1.41$ & $0.24-2.09$ & $1.69-6.03$ & $2.09-5.05$ \\
$<1.4$ mg $^{*}$ & $47.5 \%$ & $75 \%$ & $56.6 \%$ & $0 \%$ & $0 \%$ \\
$<0.7$ mg $^{\#}$ & $8.2 \%$ & $12.5 \%$ & $17.4 \%$ & $0 \%$ & $0 \%$ \\
Erythrocyte glutathione reductase activation coefficient & & \\
mean \pm s.d. & $1.22 \pm 0.18$ & $1.38 \pm 0.16 \mathrm{a}$ & $1.25 \pm 0.17 \mathrm{~b}$ & $1.21 \pm 0.19 \mathrm{~b}$ & $1.13 \pm 0.11^{\mathrm{c}}$ \\
$>1.4$ & $15 \%$ & $25 \%$ & $22 \%$ & $17 \%$ & $0 \%$ \\
$1.25-1.4$ & $16 \%$ & $75 \%$ & $17 \%$ & $0 \%$ & $11 \%$ \\
$<1.25$ & $69 \%$ & $0 \%$ & $61 \%$ & $83 \%$ & $89 \%$ \\
\hline
\end{tabular}

"RDNA, \# 50\% RDNA

$a, b, c$ : different letters in the same row indicate significant differece at $p<0.05$

Although daily intake averaged $2.24 \mathrm{mg}$, large individual variation ( ranging from 0.24 to $6.03 \mathrm{mg}$ ) existed due to difference in dietary selection and utilization of supplements. Nearly half $(47.5 \%)$ of the subjects studied had an intake lower than the RDNA; among these, 5 were lower than $50 \%$ of the RDNA. 
When ranked in a high to low order, the daily riboflavin intake was $C=D$ $>B=A$, which paralleled the reduction of $A C$; the frequency of an intake less than RDNA was $A>B>C=D$, and the prevalence of deficiency was $A>B>C$ $=D$. Significant inverse correlation existed between the $A C$ and riboflavin intake from either the supplement $(r=-0.4289, p<0.001)$ or the total intake $(r=$ $-0.4678, p<0.001$ ), indicating reduced risk of deficiency with increasing intake, and that prenatal supplement is more effective than milk in supporting the riboflavin nutriture of pregnant women.

\section{DISCUSSION}

In developed western societies, riboflavin deficiency is not a common nutritional problem for the general population due to comparatively higher consumption of milk and dairy products and fortification of cereal products . However, by measurement of AC EGR, reports from western societies have indicated the possibility of a high occurrence of riboflavin deficiency in expectant mothers as compared to nonpregnant women $(10,11)$, and an increasing need for riboflavin with the progression of pregnancy (12). Although national data indicated an improvement in riboflavin status in general population in Taiwan $(1,4)$, the prevalence of deficiency in late pregnancy evaluated with AC EGR was still more than $30 \%$ in this study. This was slightly better than the previous report of $45 \%$ in urban area (3), but is still high. This biochemical result was consistent with a recent dietary survey for pregnant women, which indicated an daily $B_{2}$ intake of only $64 \%$ RDNA during gestation (13). The prevalence of deficiency remained as high even in postpartum, this probably reflected the average prepregnant level of riboflavin nutriture. The riboflavin status for pregnant women has not been effectively improved, regardless of improved living standard. It is very unlikely that the reduced enzyme activity resulted from general or protein malnutrition because the dietary records of the subjects studied indicated an energy intake of $1815 \pm 407$ $\mathrm{kcal} /$ day and a protein intake of $78 \pm 26 \mathrm{~g} /$ day. Analysis of the riboflavin sources for the pregnant women in this study have provided some clues of the problem.

For subjects consuming no milk and no supplement, the diet provided an daily average of $0.99 \mathrm{mg}$ riboflavin. The majority of the subjects in this group had an intake less than the RDNA, and all of them were either marginally or severely deficient by the criterion of $A C$. If milk was consumed, daily riboflavin intake increased slightly to $1.14 \mathrm{mg}$, and $A C$ decreased significantly with a prominant reduction in deficiency prevalence. However, the range of riboflavin intake ( 0.24 to $2.09 \mathrm{mg} / \mathrm{day})$ in this group is wide, reflecting the wide variation in individual tolerance of milk, and deficiency in this group (39\%) is not neglegible. When supplement was taken, the riboflavin intake was about 3 times that from the diet, and both $A C$ and deficiency prevalence were effectively reduced. It is not clear why $A C>1.25$ still existed in some subjects of adequate riboflavin intake. To provide adequate riboflavin for pregnancy, it is apparent that Chinese 
diet alone is not sufficient, and milk has a limited effect, while supplement is most effective. Since there is no national practice of riboflavin fortification, and subjects might not be aware of moderate deficiency due to lack of clinical symptoms, nutritional education and dietary guidance need to be emphasized.

In Chinese custom, Postpartum diets consist of large amounts of muscle and organ meat, and riboflavin intake in one study was estimated to reach $193 \%$ of the RDNA (13). The dietary pattern for the subjects in this study is similar to the one mentioned above, yet the riboflavin status showed no significant improvement in postpartum compared to that in late pregnancy. Since meat is usually well cooked in soups, it is speculated that loss of riboflavin or change of bioaviailability from these food may contribute to such results. Although riboflavin is heat stable, it is liable to oxidation during food preparation and storage. Riboflavin availability from Chinese cuisine has not been studied.

It is noted that in this study the highest $A C$ average (1.27) and highest frequency of $A C>1.25(59 \%)$ both occurred at delivery. Although it was possible that riboflavin status further deteriorated toward term, other mechanisms are worthy of consideration since Vir et al. (11) also reported a higher incidence of $A C>1.20$ in early ( 3 days) postpartum compared to 2 nd and 3rd trimester, which cannot be accounted for by progressive deterioration of the riboflavin nutriture with the advancement of pregnancy. It is speculated that erythrocyte riboflavin may be depleted by high oxygen consumption due to strenous labor, and its repletion is not accomplished immediately after delivery. Investigation of this possible mechanism is warranted.

Many previous reports $(10,14-19)$ have indicated that riboflavin status in newborns, as measured by riboflavin concentration, EGR activity, or AC EGR, is usually better than maternal status. The same result was observed in this study that $A C$ of cord blood was significantly lower than that of mother's blood. One mechanism to protect the fetus from mild maternal deficiency is placenta conversion of FAD from maternal blood to free form for transplacenta passage and further metabolic trapping by conversion to FMN in fetus (20). Two other mechanisms: a better apoenzyme-coenzyme binding (17) or an active mechanism of placenta to favor fetal uptake (21) might also contribute to this protection. However, this protection is not without the danger that severe deficiency may result in fetal deficiency, as reported in underdeveloped countries (22).

It is concluded that riboflavin status of Chinese pregnant women but not newborns was impaired by inadequate dietary intake, and that prenatal vitamin supplement was effective in alleviating the deficiency and should be recommended to expectant mothers. 
The author is very grateful to the subjects for their cooperation, to Dr. M.T. Yang and Dr. L.-C. Chan for their clinical assisstances, and to Miss Chao for her technical assistance.

\section{REFERENCES}

1. Huang P-C, Yu S-L, Lee S-M, Kao M-D, Lee N-Y, Hong C-L, Wu T-H, Yaung C-L. Dietary survey in Taiwan area, 1980-81. J Chinese Nutr Soc 1983;8:1-20.

2. Department of Health. Recommended Daily Nutrient Allowances. 4th ed., 1987, Taipei, Taiwan.

3. Kao MD. Application of the erythrocyte glutathione reductase assay in evaluating riboflavin nutritional status of pregnant women in the central part of Taiwan. J Chinese Nutr Soc 1980;5:41-54.

4. Lee N-Y, Chu Y-C, Chang C-P, Shieh M-J, Kao M-D. Dietary survey in Taiwan Area, 1986-1988. J Chinese Nute Soc 1991;16:39-60.

5. Tung T-C, Huang P-C, Li H-C. Composition of foods used in Taiwan. J Formosan Med Assoc 1961;60:973-1005.

6. Huang P-C, Wei H-N, Huang S-L, Yu S-L. Composition of Foods used in Taiwan - Supplement. J Chinese Nutr Soc 1978;3:11-15.

7. Tillotson JA, Sauberlich HE. Effect of riboflavin depletion and repletion on the erythrocyte glutathione reductase in the rat. J Nutr 1971;101:1459-66.

8. Bamji MS. Glutathione reductase axtivity in red blood cells and riboflavin nutritional status in humans. Clin Chim Acta 1969;26:263-9.

9. Sharada D, Bamji MS. Erythrocyte glutathione reductase activity and riboflavin concentration in experimental deficiency of some water soluble vitamins. Int J Vit Nutr Res 1972;42:43-9.

10. Berg H, Schreurs WHP, Joosten GPA, Evaluation of the vitamin status in pregnancy. Int J Vit Nutr Res 1978;48:12-21.

11. Vir SC, Love AHG, Thompson W. Riboflavin status during pregnancy. Am J Clin Nutr 1981;34:2699-2705

12. Heller S, Salkeld RM, Korner WF. Riboflavin status in pregnancy. Am J Clin Nutr 1974;27:1225-30. 
13. Chang S-J. Studies on the nutrient intakes of pregnant and lactating women from Tainan area. J Chinese Nutr Soc 1991;16:101-118.

14. Clarke HC. Relationship between whole-blood riboflavin levels in the mother and in the prenate. Am J Obstet Gynecol 1971;111:43-5.

15. Baker $H$, Frank $O$, Thomson AD, Langer A, Munves ED, Angelis $B$, Kaminetzky HA. Vitamin profile of 174 mothers and newborns at parturition. Am J Clin Nutr 1975;28:56-65.

16. Knobloch E, Hodr R, Janda J, Herzmann J, Houdkova V.

Spectrofluorimetric micromethod for determining riboflavin in the blood of newborn babies and their mothers. Int J Vit Nutr Res 1979;49:144-51.

17. Bamji MS. Enzymatic evaluation or thiamin, riboflavin and pyridoxine status of parturient women and their newborn infants. Br J Nutr 1976;35:259-65.

18. Kirshenbaum NW, Dancis J, Levitzz M, Lehanka J, Young BK. Riboflavin concentration in maternal and cord blood in human pregnancy. Am J Obstet Gynecol 1987;157:748052.

19. Vudhivai $N$, ongpaew $P$, Prayurahong $B$, Kwanbunjan $K$, Migasena $P$, Chitwattanakorn $M$, Hempfling $A$, Schelp F-P. Vitamin $B_{1}, B_{2}$ and $B_{6}$ in relation to anthropometry, hemoglobin and albumin of newborns and their mothers from northeast Thailand. Int J Vit Nutr Res 1989;60:75-80.

20. Lust JE, Hagerman DD, Villee CA. The transport of riboflavin by human placenta. J Clin Invest 1954;33:38-40

21. Dancis J, Lehanka J, Levita M. Placental transport of riboflavin: differential rates of uptake at the maternat and fetal surfaces of the perfused human placenta. Am J Obstet Gynecol 1988;158:204-10.

22. Bates CJ, Prentice AM, Watkinson M, Morrell P, Foord FA, Watkinson A, Cole TJ, Whitehead RG. Efficacy of a food supplement in correcting riboflavin deficiency in pregnant Gambian women. Human Nutr Clin Nutr 1984;38C:36374.

Accepted for publication November 9, 1992. 